\title{
ON SOME NEW NONLINEAR VOLTERRA-FREDHOLM TYPE DISCRETE INEQUALITIES AND ITS APPLICATIONS
}

\author{
Subhash KendRe And NAGesh Kale
}

Abstract. In this paper, we develop some extensions and generalizations of some new nonlinear Volterra-Fredholm type discrete inequalities. These inequalities can be used as handy tools in the study of class of nonlinear Volterra-Fredholm sum-difference equations and its variants to obtain bound on the unknown function and analysis of various properties of solutions.

Mathematics subject classification (2010): 26D15,65Q05,39A70,39A10.

Keywords and phrases: Nonlinear discrete inequalities, Volterra-Fredholm type, explicit bounds, sumdifference equations.

\section{REFERENCES}

[1] Pachpatte, B.G., Inequalities for Finite Difference Equations, Marcel Dekker, Inc., New York, (2002).

[2] Salem Sh. And Raslan K.R., Some New Discrete Inequalities and Their Applications, Journal of Inequalities in Pure and Applied Mathematics, Vol 5, Issue 1, (2004).

[3] QING-HuA MA, Some New nonlinear Volterra-Fredholm-type dicsrete inequalities and their Applications, Journal of Computational and Applied Mathematics, 216, (2008), (451-466).

[4] Qing-Hua Ma And Wing-Sum Cheung, Some New Nonlinear difference inequalities and their Applications, Journal of Computational and Applied Mathematics, 202, (2007), (339-351).

[5] ZIZUn Li, Gronwall-Bellman Type Nonlinear Sums-Difference Inequalities and Applications in Difference Equations, Journal of Mathematical Research with Applications, Jul., 2018, Vol. 38, No. $4,(393-410)$.

[6] Run Xu And Xiangting Ma, Some new retarded nonlinear Volterra-Fredholm type integral inequalities with maxima in two variables and their applications, Journal of Inequalities and Applications, (2017) 2017:187.

[7] QING-HUA MA, Estimates on some power nonlinear Volterra-Fredholm type discrete inequalities and their applications, Journal of Computational and Applied Mathematics, 233(2010): 2170-2180.

[8] T. H. GRONWALL, Note on the derivatives with respect to a parameter of the solutions of a system of differential equations, Annals of Mathematics, vol. 20, no. 4, pp. 292-296, 1919.

[9] R. Bellman, The stability of solutions of linear differential equations, Duke Mathematical Journal, vol. 10, pp. 643-647, 1943.

[10] L. OU-LiAng, The boundedness of solutions of linear differential equations $y^{\prime \prime}+A(t) y^{\prime}=0$, Advances in Mathematics, vol. 3, pp. 409-415, 1957.

[11] B. G. PAChPATte, Inequalities for Differential and Integral Equations, Academic Press, New York, NY, USA, 1998.

[12] Pachpatte, B.G., Discrete inequalities in two variables and their applications, Radovi Math.6 ,(1990), 235-247 .

[13] Singare, S. M. And Pachpatte, B. G., Wendroff type discrete inequalities and their applications, Jour. Math.Phys. Sci.13, (1979), 149-167.

[14] E. H. YANG, On some nonlinear integral and discrete inequalities related to Ou-Iang's inequality, Acta Mathematica Sinica, vol. 14, no. 3, pp. 353-360, 1998. 
[15] W. S. Cheung AND Q. H. MA, On certain new Gronwall-Ou-Iang type integral inequalities in two variables and their applications, Journal of Inequalities and Applications, vol. 2005, no. 4, pp. $347-$ 361, 2005.

[16] P.Y.H. PANG, R.P. AgARwal, On an integral inequality and discrete analogue, J. Math. Anal. Appl., 194 (1995) 569-577.

[17] LEES, M., Approximate solutions of parabolic equations, J.Soc. Ind. Appl. Math.,7(1959), 167-183. 